\title{
Traumatic Posterior Dislocation of Hip with Ipsilateral Fracture of Shaft of Femur: Temporary Fixator-assisted Reduction and Final Fixation with Interlocking Nail
}

\author{
Rajesh Rana ${ }^{1}$, Saroj K. Patra ${ }^{2}$, Susanta Khuntia ${ }^{1}$, Mantu Jain ${ }^{1}$, Bishnu P. Patro ${ }^{1}$ \\ 1. Orthopaedics, All India Institute of Medical Sciences, Bhubaneswar, IND 2. Trauma \& Orthopaedics, All India \\ Institute of Medical Sciences, Bhubaneswar, IND
}

Corresponding author: Rajesh Rana, rajesh.rana66@gmail.com

\begin{abstract}
Ipsilateral fracture of the shaft of femur and dislocation of the hip are very rare injuries. There always exists a dilemma regarding the treatment to reduce hip and choosing the appropriate method of fixation for a femur fracture, and a clear consensus is yet to be reached. A number of treatment methods such as the open reduction of femur and fixation followed by hip reduction have been tried so far. Ipsilateral fractures and dislocation occur due to high-energy trauma, and reduction of hip dislocation is considered as an orthopedic emergency. Here, we report a case in which we tried a novel approach by temporarily fixing the femur with an external fixator and reducing the hip dislocation. In the next sitting, we performed femur fixation in a closed manner with an interlocking intramedullary nail. We recommend that this novel method of treatment can be used for such types of injuries.
\end{abstract}

Categories: Orthopedics, Trauma

Keywords: fracture shaft of femur, ipsilateral hip dislocation, fixator, reduction

\section{Introduction}

Ipsilateral fracture of the shaft of femur and dislocation of the hip are very rare injuries [1]. There always exists a dilemma regarding the treatment to reduce hip and choosing the appropriate method of fixation for a femur fracture. These types of injuries occur due to high-impact forces which are common nowadays due to road traffic accidents. Here, we report the case of an 18-year-old male patient with ipsilateral hip dislocation and a fracture in the shaft of femur. The patient was treated with a temporary external fixator followed by a reduction of hip dislocation. Finally, the fixator was removed followed by a closed reduction and internal fixation of the fractured shaft of femur with an interlocking nail [2].

Received 08/20/2019 Review began 08/22/2019 Review ended 08/22/2019 Published 08/26/2019

(c) Copyright 2019 Rana et al. This is an open access article distributed under the terms of the Creative Commons Attribution License CC-BY 3.0., which permits unrestricted use, distribution, and reproduction in any medium, provided the original author and source are credited.

\section{Case Presentation}

An 18-year-old male patient reported to our ED following a road traffic accident with severe pain in the right hip and right thigh. The patient had a deformity of the right hip and thigh, and was unable to walk. On clinical examination, we found that he had flexion-adduction deformity of the right hip. His leg and foot showed external rotation and abduction. There was tenderness and abnormal mobility at the right thigh. In addition, there was tenderness at the right hip joint and the femoral head was palpable in the gluteal region. The range of movements at the right hip was grossly restricted and painful. There was no distal neurovascular deficit noted.

After providing the advanced trauma life support in causality, the patient was sent for radiography. X-rays of the pelvis with both hips and of the right thigh with hip and knee were taken (Figure 1). 


\section{Cureus}

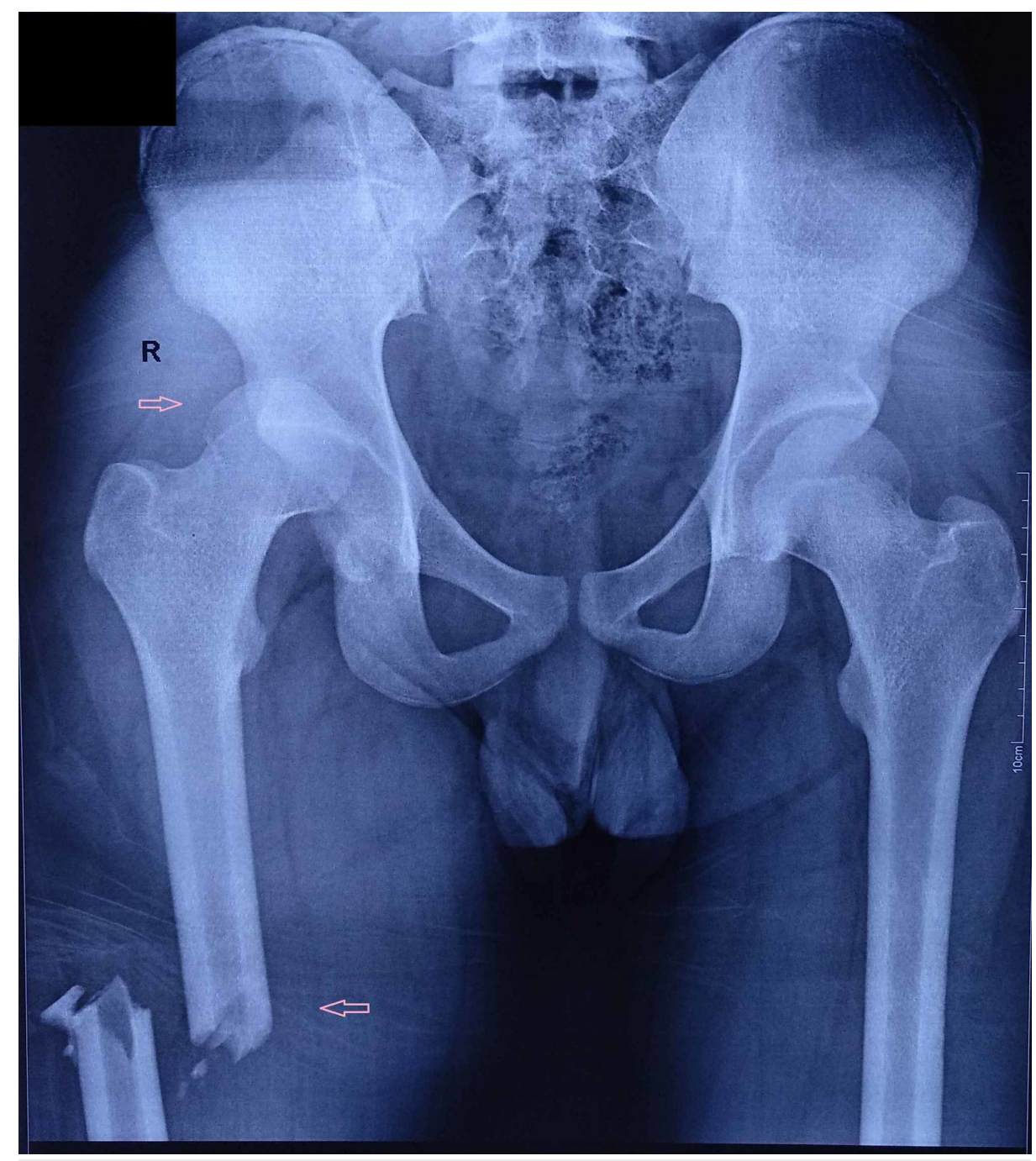

FIGURE 1: Preoperative radiograph.

CT scan of the hip and pelvis was also taken to exclude acetabulum fractures (Figure 2). 


\section{Cureus}

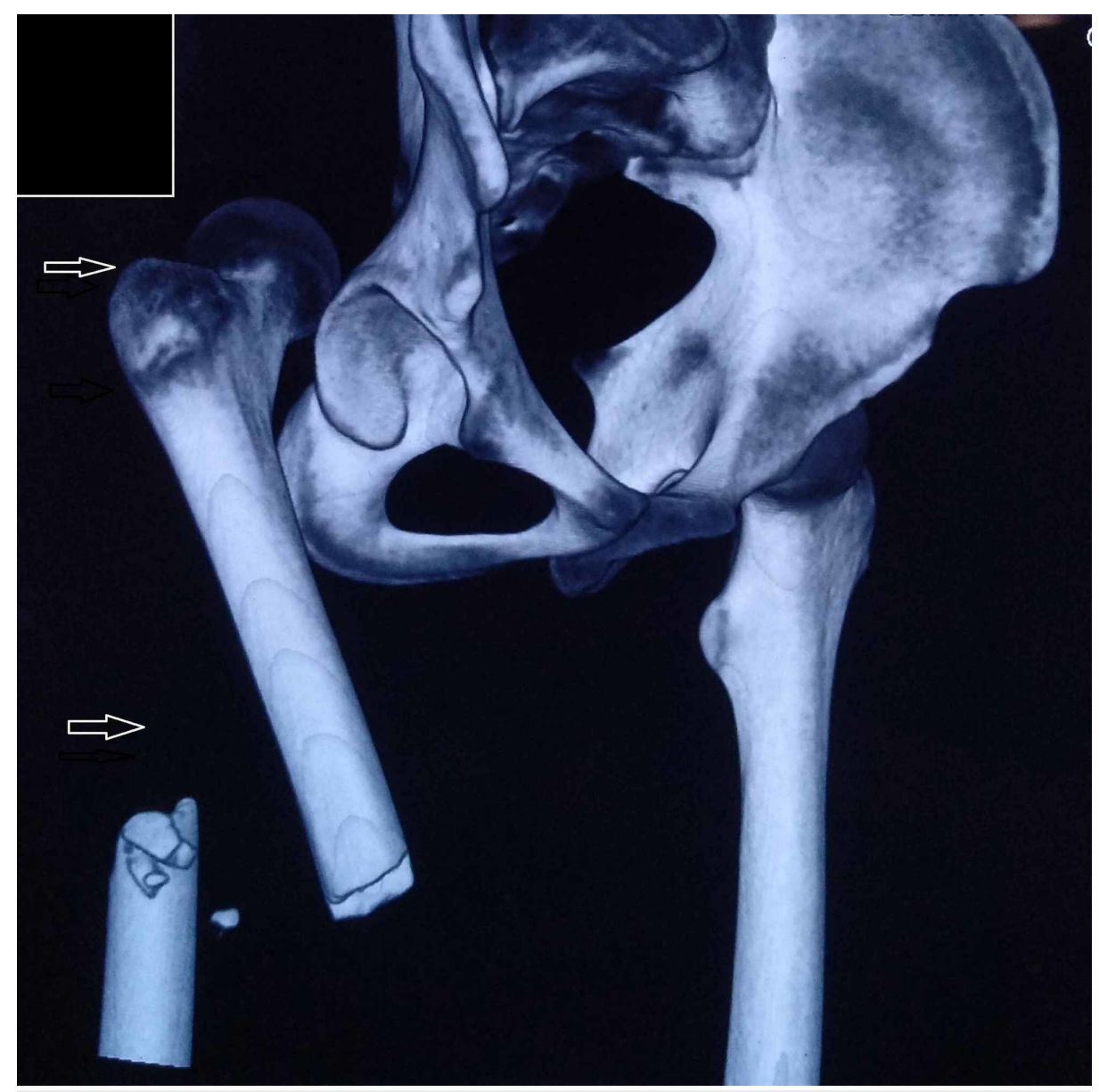

FIGURE 2: Preoperative CT scan.

From the radiograph, we confirmed that there was a fracture in the shaft of femur and a posterior dislocation in the hip. The patient was taken to an emergency OT and subjected to closed manipulation of the hip joint. As there was a fracture in the shaft of femur, the force was not transmitted to the hip joint and we are unable to reduce the hip dislocation. At that moment, we had two options: open reduction and external fixation, and closed manipulation of the dislocation of the hip joint. We placed a temporary external fixator in the femur under anesthesia, and performed closed manipulation and reduction of dislocation of the hip using the Allis method (Figure 3). 


\section{Cureus}

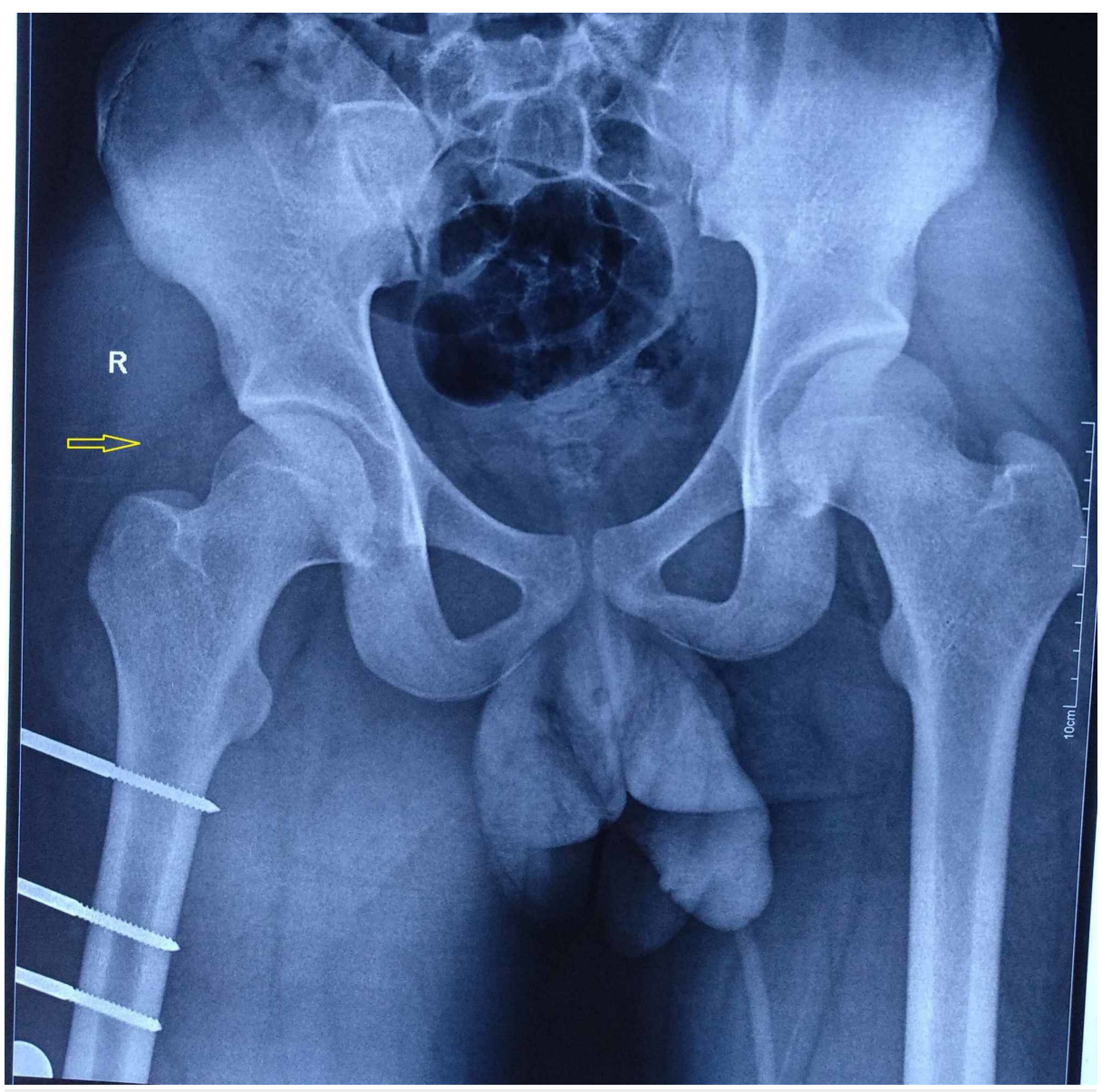

FIGURE 3: Reduced hip with external fixator in the femur.

The patient was subjected to final fixation of the femur shaft fracture after one day in elective OT. Femur shaft fracture was fixed with a closed reduction and an internal fixation with an intramedullary femur interlocking nail (Figure 4). 


\section{Cureus}

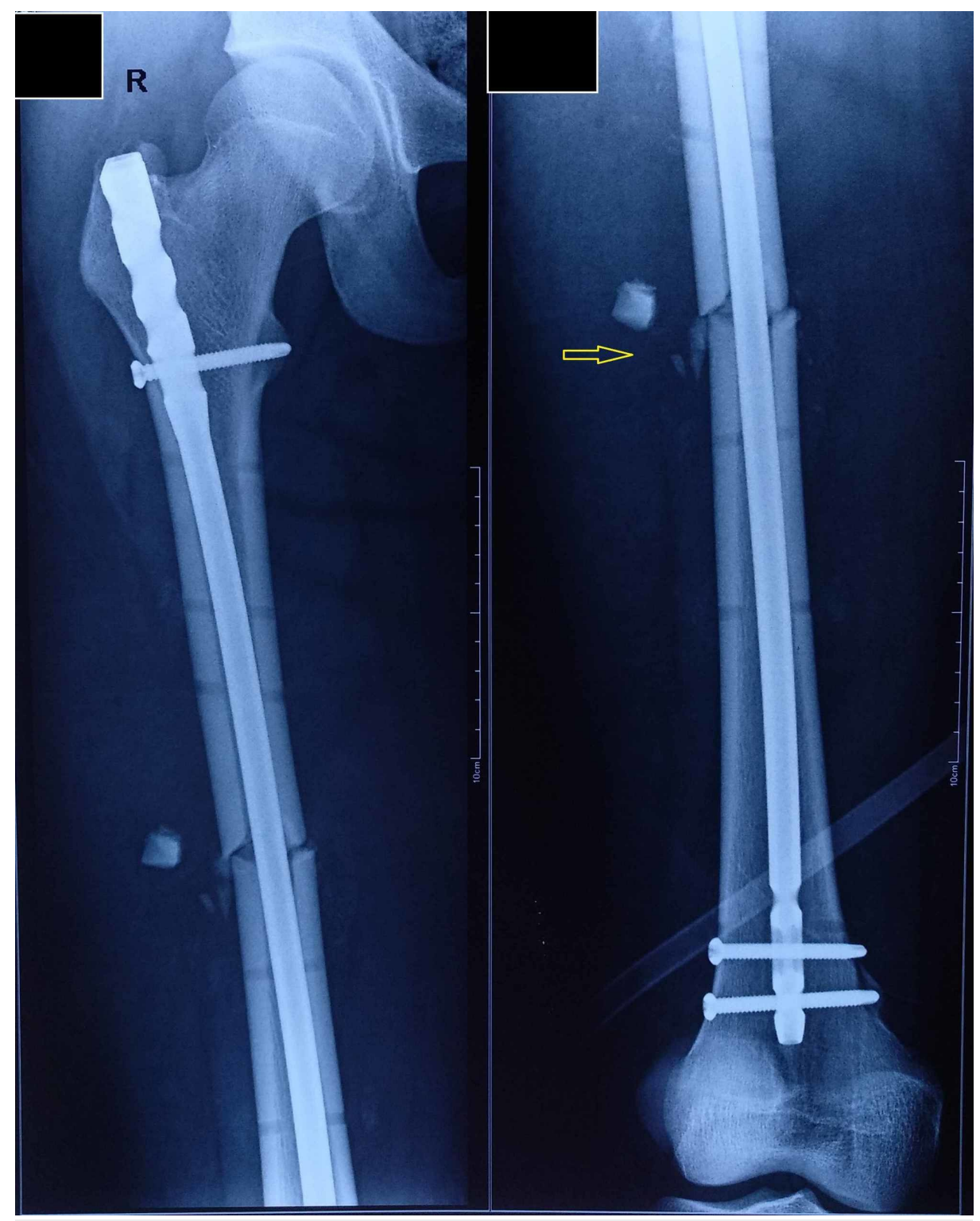

FIGURE 4: Postoperative radiograph with the intramedullary nail.

The operation was done on a traction table under the guidance of fluoroscopy.

Postoperatively, the patient's legs were placed on an abduction pillow and physiotherapy was started. Lowmolecular-weight heparin was given as deep vein thrombosis (DVT) prophylaxis. The patient was not allowed weight-bearing for two weeks. Gradually, he was allowed partial weight-bearing based on his tolerance.

\section{Discussion}

Ipsilateral fracture of the shaft of femur and dislocation of the head are very rare injuries. So far, no consensus has been reached on the treatment of such injuries. Reduction of dislocation is considered an emergency; however, it is difficult [3] to perform because direct transmission of traction is not possible due to fracture in the shaft of the femur. This type of injuries generally occurs due to two types of forces: axial force that causes the hip dislocation and lateral force that causes fracture of the shaft of femur [4]. Dislocation of the hip is often missed to be diagnosed [5]. This can be avoided with a proper clinical examination and radiological investigation. Thus, CT scan of the pelvis and hip is always helpful in excluding other acetabulum or pelvic fractures.

Different methods such as placing Steinmann pin in the proximal femur and reduction have been tried by various authors. These are followed by open reduction and internal fixation. Moreover, closed or indirect reduction is more favorable than open reduction unless there is a need for internal fixation for an acetabular or proximal femur fracture. Many complications are often associated with an open reduction [6] and internal 
fixation, which include hemorrhage, loss of fracture, infection, delay in union and avascular necrosis of the head of femur, and sciatic nerve injury [7]. In our case, using an external fixator helped in indirect reduction of hip dislocation and precluded open reduction-related complications. The use of the fixator followed by closed reduction and internal fixation with an interlocking nail gave satisfactory results without any complication.

\section{Conclusions}

Ipsilateral fracture of the femur shaft and hip dislocation are rare injuries, and always difficult to be diagnosed and treated. These injuries are always considered as an orthopedic emergency. In such conditions, fixator-assisted reduction of hip dislocation followed by closed reduction and internal fixation with an intramedullary nail gives satisfactory results with minimal complications.

\section{Additional Information}

\section{Disclosures}

Human subjects: Consent was obtained by all participants in this study. Conflicts of interest: In compliance with the ICMJE uniform disclosure form, all authors declare the following: Payment/services info: All authors have declared that no financial support was received from any organization for the submitted work. Financial relationships: All authors have declared that they have no financial relationships at present or within the previous three years with any organizations that might have an interest in the submitted work. Other relationships: All authors have declared that there are no other relationships or activities that could appear to have influenced the submitted work.

\section{References}

1. Ehtisham SM: Traumatic dislocation of hip joint with fracture of shaft of femur on the same side . J Trauma. 1976, 16:196-205. 10.1097/00005373-197603000-00004

2. Alhammoud A, Alnouri M, Arbash MA, Baco AM: Posterior hip dislocation with ipsilateral femoral head and shaft fracture - using a temporary external fixator as a method for closed reduction. J Orthop Case Rep. 2016, 6:44-46.

3. Verdonk R, de Smet L: Hip dislocation combined with femoral shaft fracture. Two cases treated with the Lardennois hoop. Acta Orthop Scand. 1984, 55:185-186. 10.3109/17453678408992334

4. Kassou N, Naam A, El Alami B, Abdulrazak S, Marzouki A, Lahrach K, Boutayeb F: Traumatic dislocation of the hip associated to ipsilateral femoral shaft fracture in a racing driver. IOSR-JDMS. 2017, 16:81-84.

5. Dehne E, Immermann EW: Dislocation of the hip combined with fracture of the shaft of the femur on the same side. J Bone Joint Surg Am. 1951, 33:731-745.

6. Harper MC: Traumatic dislocation of the hip with ipsilateral femoral shaft fracture: a method of treatment . Injury. 1982, 13:391-394.

7. Shannak AO: Bilateral traumatic dislocation of the hips with ipsilateral femoral fracture . Clin Orthop Relat Res. 1987, 215:126-129. 